\title{
FUNCTIONAL OUTCOME OF PROXIMAL HUMERUS FRACTURE MANAGED SURGICALLY BY JOSHI'S EXTERNAL STABILIZING SYSTEM
}

\author{
Prakriti Raj Kandel, ${ }^{1}$ Bipan Shrestha, Kishor Man Shrestha, ${ }^{1}$ Shreshal Shrestha, ${ }^{1}$ Pradip Chhetri ${ }^{2}$
}

\begin{abstract}
INTRODUCTION

The ideal management of proximal humerus fracture is still controversial despite various treatment options. Conservative treatment with slab is fraught with shoulder stiffness and malunion while surgical treatment with plates and nail is fraught with infection and blood loss. Therefore, Joshi External Stabilization System (JESS) being a minimally invasive percutaneous procedure can be the ideal treatment for these fractures.
\end{abstract}

\section{MATERIAL AND METHODS}

This prospective and observational hospital based study was carried out in Orthopedics Department, Universal College of Medical Sciences Teaching Hospital (UCMS-TH) from December 2018 to January 2021. All patients with traumatic proximal humerus fracture who fulfilled the inclusion criteria were enrolled in the study and were treated with JESS. Fracture was classified according to Neer classification and functional outcome was assessed according to Constant Murley Score (CMS) system. Post-operatively patients were regularly followed at 6 weeks, 3 months and 6 months.

\section{RESULTS}

There was statistically significant difference in VAS score $(p<0.05)$ measured at six weeks, three months and six months; and CMS $(\mathrm{p}<0.05)$ at three months and six months. There was statistically significant difference between fracture type (Neer type) and fracture union $(p<0.05)$. But the association between functional outcome and type of fracture was statically insignificant $(p>0.05)$.

\section{CONCLUSION}

Displaced proximal humerus fracture when treated surgically with JESS has good functional and radiological outcome. It produces less pain, less stiffness and greater range of motion (ROM).

\section{KEYWORDS}

Constant Murley score, JESS, Proximal humerus fracture.

1. Department of Orthopaedics and Trauma Surgery, Universal College of Medical Sciences, Bhairahawa, Nepal

2. Department of Community Medicine, Universal College of Medical Sciences, Bhairahawa, Nepal

DOI: https://doi.org/10.3126/jucms.v9i02.41990

For correspondence

Dr. Prakriti Raj Kandel

Department of Orthopaedics \& Trauma Surgery,

Universal College of Medical Sciences

Bhairahawa, Nepal.

E-mail:pratul22@gmail.com 


\section{INTRODUCTION}

Fractures of the proximal humerus, which accounts for $4 \%$ to $5 \%$ of all fractures, are a common fracture affecting elderly patients with osteoporotic bones. ${ }^{1,2}$ In elderly patients, this fracture is the third most common fracture after Hip and Colles' fractures. ${ }^{3}$ Fall from height and Road traffic accident (RTA) is the common mode of injury in elderly and young patients respectively. These fractures are more common in female individuals, with a ratio of 2 to $3 .^{1,2}$

Proximal humerus fractures have been managed both conservatively and surgically. ${ }^{4}$ Conservative treatment with shoulder immobilizer and slab is a valid option for simple and undisplaced fracture but has disadvantage of shoulder stiffness, loss of reduction and malunion. ${ }^{2}$ For complex and displaced fracture, surgical treatment is the best option which counteracts the disadvantages of conservative treatment. ${ }^{5,6}$ Various surgical treatments has been suggested for these fracture like closed reduction and percutaneous pinning (CRPP), plate and screws, intramedullary interlocking nailing (IMIL) and JESS. ${ }^{5}$ CRPP is the simple, safe and minimally invasive procedure but has risk of fracture stability. ${ }^{6}$ Proximal humerus plating is the stable fixation procedure but has risk of blood loss, injury to neurovascular structure and infection. ${ }^{7,8}$ IMIL is a minimally invasive procedure with adequate stability but has high incidence of shoulder impingement syndrome and rotator cuff injury.

JESS being a percutaneous minimally invasive procedure, is safe and suitable procedure for simple as well as complex proximal humerus fracture. Moreover, it is simple and easily applicable, cost effective and light weight external fixator than other common external fixators. The main advantage of JESS over commonly performed CRPP is that JESS is highly stable implant than CRPP and it allows early shoulder ROM exercises from day one of surgery which avoids the chances of shoulder stiffness commonly seen in CRPP. Thus, this study was planned to assess the functional and radiological outcome of proximal humerus fracture managed surgically with JESS.

\section{MATERIAL AND METHODS}

A prospective longitudinal, observational study was designed and approved by IRC of UCMS-TH, Bhairahawa, Nepal (UCMS/IRC/204/18). The sample size was calculated by below formula which is approximately 59 and we took a convenient sample of 60 patients.

$\mathrm{n}=\mathrm{z}^{2} \mathrm{pq} / \mathrm{d}^{2}[\mathrm{n}=$ required sample size; $\mathrm{p}=$ prevalence of disease; $\mathrm{q}=100-\mathrm{p} ; \mathrm{z}=1.96$ taken at $95 \%$ confidence interval; $\mathrm{d}=$ allowable error taken as $5 \% ; \mathrm{P}=2 \%, \mathrm{q}=98 \%$ ]

Data were collected from patients with proximal humerus fracture who reported to Department of Orthopaedics, UCMS-TH, Bhairahawa, Nepal, from December 2018 to January 2021.

\section{Inclusion criteria}

1. Displaced proximal humeral fractures

2. Acute injuries up to seven days

3. Age $\geq 18$ years

\section{Exclusion criteria}

1. Open fractures

2. Pathological fractures

3. Periprosthetic fractures

4. Undisplaced proximal humeral fractures

5. Congenital anomaly of the affected limb

6. Previous fracture of the affected limb

Proximal humerus fracture may occur at the surgical neck, anatomic neck, greater tuberosity, and lesser tuberosity. The Neer classification of proximal humeral fracture is probably the most frequently used system which divides the proximal humerus into four parts and considered not the fracture line, but the displacement as being significant in terms of classification. The four parts are the humeral head, the greater tuberosity, the lesser tuberosity and the humeral shaft. Displacement is on a per-part basis. A fracture part is considered displaced if angulations exceeds 45 degrees, or if the fracture is displaced by more than $1 \mathrm{~cm} .{ }^{10}$

Demographic data such as age, gender and address were recorded along with information regarding mode of injury, side of injury and other associated injuries. The patients with proximal humerus fracture were initially assessed for any lifethreatening injuries according to Advanced Trauma Life Support protocol (ATLS) and were managed accordingly. The fractures were reduced and "U" slab immobilization was given in emergency or OPD for maintaining alignment of limb. All preoperative investigations including radiographs were sent along with CT scan if needed. Then the patient was planned for surgery after getting clearance on pre-anesthetic check-up. All cases were operated by a single surgeon.

\section{Surgical technique}

All procedures were performed under regional anesthesia. Patient was given a beach chair position with a sandbag under the ipsilateral scapula. K-wires which have $2 \mathrm{~mm}$ threads were introduced avoiding the area which is $5 \mathrm{~cm}$ from the lateral border of the acromion on the lateral surface of the arm to avoid damage to the motor branch of the axillary nerve. A closed reduction of the fracture was performed under image intensifier. K-wires were passed from the distal shaft into the inferiomedial part of the head (so-called calcar). At least 2 but preferably $3 \mathrm{~K}$-wires were passed in the proximal (head) 
fragment, one directly lateral and the other 2 making a 45degree angle anteriorly and posteriorly, respectively to achieve a biplanar C-shaped construct, which was used to manipulate the proximal (head) fragment. Another three Kwires were drilled perpendicularly in the distal fragment (Fig. 2). The proximal wires were connected to form a C-shaped construct, and the distal 3 wires were connected with a straight rod. The distal and the proximal construct were interconnected with $3 \mathrm{~mm}$ rods and clamps. The reduction was then rechecked under image intensifier and final tightening of the clamps was performed to form a single stable construct (Fig. 3).

$\mathrm{X}$-ray of the arm in anterior posterior view and axillary view was taken of the affected shoulder immediate after surgery. Pin track dressing was done on the second postoperative day and later weekly depending on the condition of the pin. Passive-assisted and active-assisted mobilization of the shoulder was started as soon as possible after surgery. Patient was discharged depending upon the condition of the pin track wound and the extent of swelling or other associated conditions.

All patients were followed up at six weeks, three months and six months. Standard AP and axillary X-rays of the affected shoulder were done on each follow up. The clinical and radiographic results were recorded during each follow-up to ensure that no pin has migrated, no loss of reduction has occurred, evidence of callus formation and consolidation of fracture. VAS score ${ }^{11}$ was assessed at six weeks, three months and six months follow up. Functional assessment using Constant Murley score ${ }^{12,13}$, was done at $3^{\text {rd }}$ and $6^{\text {th }}$ month. Any complications such as infection or hardware complications that occurred were recorded. The JESS fixator was removed at six to eight weeks upon radiologic union. Radiological union was considered when mature callus was seen in at least three cortices in two radiographic views

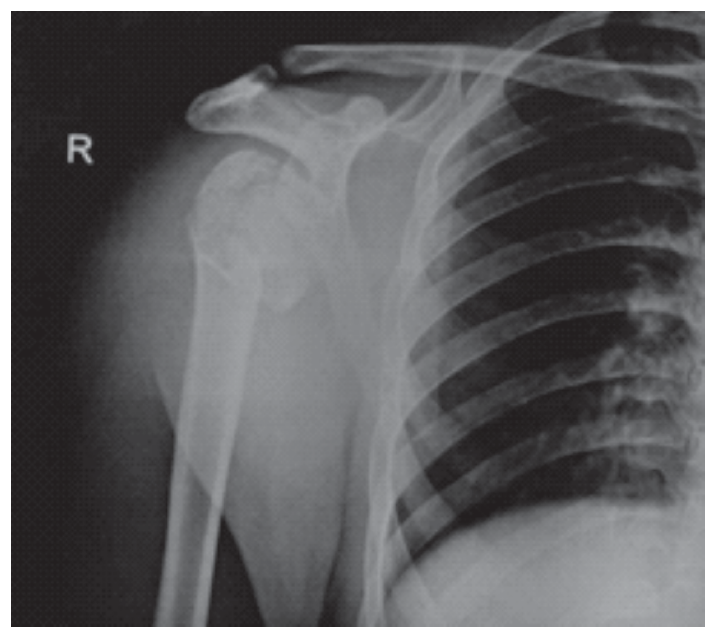

Figure 1. Preoperative $x-$ ray

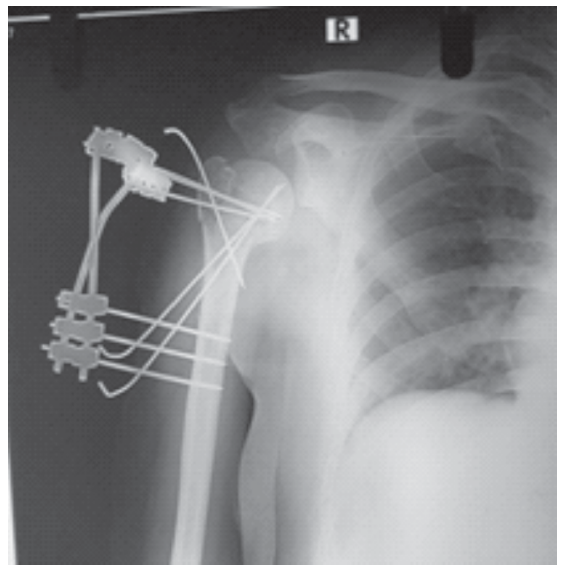

Figure 2. Postoperative x-ray

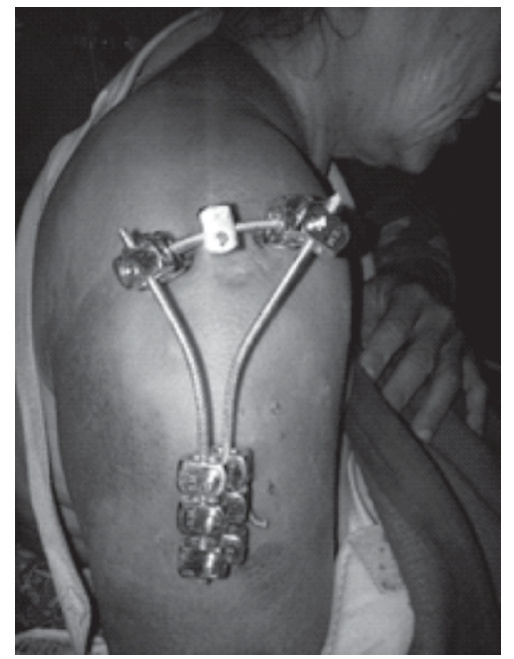

Figure 3. Joshi external stabilizing system constructs

\section{Statistical analysis}

All the data were collected as patient's demographic profile, general history, clinical and radiological findings, its management and regular follow up. Data were entered and analyzed by SPSS 21. Descriptive Statistics like frequency, percentage, mean and standard deviation were used to analyze the data. Chi-Square test and Paired T test were used as inferential statistics. $p$ value less than 0.05 was considered as statistically significant.

\section{RESULTS}

A total of 60 patients included in this study with mean age $54.83 \pm 19.01$ (21-84) years. Majority of cases were males $(60 \%)$, fall on ground was the most common mode of injury $(53.3 \%)$ and right side was commonly affected (56.7\%). Most of the fractures were Neer classification Type 2 (53.3\%), average interval between trauma and surgery was $3.2 \pm 1.54$ (1-7) days and average hospital stay was $6.3 \pm 1.78$ (3-9) days. 
Pin track infection (6.7\%) and pin migration (3.3\%) was the only complication seen (Table 1 ).

Table 1. Demographic profile, general characteristic and fracture complication

\begin{tabular}{lccc}
\hline \multicolumn{1}{c}{ Variable } & $\begin{array}{c}\text { Frequency } \\
\text { (n) }\end{array}$ & $\begin{array}{c}\text { Percentage } \\
(\%)\end{array}$ & $\begin{array}{c}\text { Mean } \pm \text { SD; } \\
\text { Range }\end{array}$ \\
\hline Gender & 36 & 60 & \\
Male & 24 & 40 & \\
Female & & & $54.83 \pm 19.01 ;$ \\
Age (years) & & & Range (21-84) \\
Side & 34 & 56.7 & \\
Right & 26 & 43.3 & \\
Left & & & \\
MOI & 28 & 46.7 & \\
RTA & 32 & 53.3 & \\
Fall injury & & & \\
Neer classification & 32 & 53.3 & \\
II & 22 & 36.7 & \\
III & 6 & 10 & \\
IV & & & $3.2 \pm 1.54 ;$ \\
Interval between trauma and surgery & & & Range (1-7) \\
(days) & & & $6.3 \pm 1.78 ;$ \\
Hospital stay (days) & & & \\
Complication & & & \\
Pin tract infection & & & \\
Pin migration & 4 & & \\
\hline & 2 & 3.3 & \\
\hline
\end{tabular}

At the end of three months and six months, we observed good results in majority of cases accounting for $36.7 \%$ and $60 \%$ respectively. The mean duration of fracture union was 7.93 \pm 0.98 (6-12) weeks. At the end of 6 months, VAS and CMS was $0.4 \pm 0.49(0-1)$ and $83.86 \pm 8.98(60-98)$ respectively (Table 2).

Table 2. Functional outcomes and fracture union

\begin{tabular}{|c|c|c|c|}
\hline Variables & $\begin{array}{l}\text { Frequency } \\
\text { (n) }\end{array}$ & $\begin{array}{c}\text { Percentage } \\
(\%)\end{array}$ & Mean \pm SD; Range \\
\hline \multicolumn{4}{|l|}{$\begin{array}{l}\text { Patient Satisfaction ( } 3 \\
\text { months) }\end{array}$} \\
\hline Excellent & 10 & 16.7 & \\
\hline Good & 22 & 36.7 & \\
\hline Fair & 16 & 26.7 & \\
\hline Poor & 12 & 20 & \\
\hline \multicolumn{4}{|l|}{$\begin{array}{l}\text { Patient Satisfaction (6 } \\
\text { months) }\end{array}$} \\
\hline Excellent & 18 & 30 & \\
\hline Good & 36 & 60 & \\
\hline Fair & 6 & 10 & \\
\hline Poor & 0 & 0 & \\
\hline Union (weeks) & & & $7.93 \pm 0.98 ;$ Range (6-12) \\
\hline VAS 6 weeks & & & $4.63 \pm 0.76$; Range (4-6) \\
\hline VAS 3 months & & & $2.63 \pm 0.99 ;$ Range (1-4) \\
\hline VAS 6 months & & & $0.4 \pm 0.49 ;$ Range $(0-1)$ \\
\hline CMS 3 months & & & $\begin{array}{c}70.43 \pm 13.65 \text {; Range }(43- \\
92)\end{array}$ \\
\hline CMS 6 months & & & $\begin{array}{c}83.86 \pm 8.98 \text {; Range }(60- \\
98)\end{array}$ \\
\hline
\end{tabular}

We observed statistically highly significant difference in VAS at six weeks and three months $(p=0.00)$, and VAS at three months and six months $(p=0.00)$ with significant improvement in VAS score. We also observed statistically highly significant difference in CMS at three months and six months $(p=0.00)$ with significant improvement in CMS score. (Table 3)

Table 3. Paired $\mathbf{T}$ test for visual analogue scale and constant Murley score

\begin{tabular}{lcc}
\hline \multicolumn{1}{c}{ Variables } & Mean \pm SD & p value* \\
\hline VAS 6 weeks & $4.63 \pm 0.76$ & 0.00 \\
VAS 3 months & $2.63 \pm 0.99$ & \\
VAS 3 months & $2.63 \pm 0.99$ & 0.00 \\
VAS 6 months & $0.4 \pm 0.49$ & \\
CMS 3 months & $70.43 \pm 13.65$ & 0.00 \\
CMS 6 months & $83.86 \pm 8.98$ & \\
\hline
\end{tabular}

*Paired T test

There was statistically significant difference between Neer fracture classification and fracture union time where Neer type II and III fractures united early than Neer type IV $(p=0.01)$ but we observed statistically no significant difference between Neer fracture classification and patient satisfaction at three months $(p=0.08)$ and 6 months $(p=0.09)$. (Table 4)

Table 4. Association of fracture union and patient satisfaction according to Neer classification

\begin{tabular}{llcccc}
\hline \multicolumn{1}{c}{ Variables } & & \multicolumn{3}{c}{ Neer Classification } & p value $^{*}$ \\
\hline & & II & III & IV & \\
Union (weeks) & 6 weeks & $6(100 \%)$ & 0 & 0 & \\
& 8 weeks & $26(50 \%)$ & $11 / 22(42.3 \%)$ & $4(7.7 \%)$ & 0.01 \\
& 12 weeks & 0 & 0 & $2(100 \%)$ & \\
\cline { 2 - 5 } Patient satisfaction (3 months) & Excellent & $8(80 \%)$ & $2(20 \%)$ & 0 & \\
& Good & $16(72.7 \%)$ & $4(18.2 \%)$ & $2(9.1 \%)$ & \multirow{2}{*}{0.08} \\
& Fair & $6(37.5 \%)$ & $6(37.5 \%)$ & $4(25 \%)$ & \\
& Poor & $2(16.7 \%)$ & $10(83.3 \%)$ & 0 & \\
\cline { 2 - 5 } Patient satisfaction (6 months) & Excellent & $14(77.8 \%)$ & $2(11.1 \%)$ & $2(11.1 \%)$ & \\
& Good & $18(50 \%)$ & $14(38.9 \%)$ & $4(11.1 \%)$ & 0.09 \\
& Fair & 0 & $6(100 \%)$ & 0 & \\
\hline
\end{tabular}

*Chi Square test

\section{DISCUSSION}

In this present study, 60 cases of proximal humerus fractures were managed surgically with JESS with mean age group $54.83 \pm 19.01$ (21 to 84 ) years which is similar to Herscovici Jr $\mathrm{D}$ et al. ${ }^{14}$ (Mean age 50, range 23-88 years) and Arshad $\mathrm{N}$ et al.7 (range 21 to 80 years). There were 36 males $(60 \%)$ and 24 females $(40 \%)$ with male to female ratio of $3: 2$ which is similar to Herscovici Jr D, et $\mathrm{al}^{14}$ (male $55 \%$ and female $45 \%$ ) and Arshad N, et al' (male 70\% and female 30\%). Major cause of fracture was fall injury $(53.3 \%)$ followed by road traffic accidents (46.7\%), which was similar to the study done by Herscovici Jr D, et al ${ }^{4}$ (50\% fall injury, $47.5 \%$ RTA). In the present study, 34 cases (57\%) were of right side while 26 cases 
(43\%) were of left side which is similar to Joshi AK, et $\mathrm{al}^{15}$ $\left(63.3 \%\right.$ right sided and $36.7 \%$ left sided) and Azhagan $\mathrm{S}$, et $\mathrm{al}^{12}$ ( $75 \%$ right sided and $25 \%$ left sided).

Majority of cases (32 cases; 53.3\%) were Neer type II followed by Neer type III and IV that accounted for 22 cases $(36.7 \%)$ and six cases $(10 \%)$ respectively which is similar to the study done by Herscovici Jr D, et al.14 (Type II-52.5\%, type III- $40 \%$ and type IV-10\%). Mean interval between trauma and surgery was $3.2 \pm 1.54$ (1-7) days which is similar to the Giovanni Vicenti, et $\mathrm{al}^{16}$ (mean 4 days, range 1-9 days). The average duration of hospital stay was $6.3 \pm 1.78$ (3-9) days which is similar to Giovanni Vicenti et all6 (mean $5.7 \pm 2.6$ days).

In this study, the average duration of fracture union was 7.93 \pm 0.98 (6-12) week which is similar to a Herscovici Jr D et al. ${ }^{14}$ (Mean 10 weeks, range 6-20 weeks). We observed superficial infection (four cases- 6.7\%) and $\mathrm{k}$ wire migration (two cases$3.3 \%$ ) as the only complication which is better than Kocialkowski A et $\mathrm{al}^{17}$ where five cases (23\%) had superficial infection and nine cases (41\%) had $\mathrm{k}$ wire migration. The reason behind less k-wire migration in present study could be due to use of threaded $\mathrm{k}$ wire.

In this study, VAS at six months was $0.4 \pm 0.49$; Range(0-1) but a study done by Magovern B, et al found that mean was 1.4. We observed statistically highly significant difference in VAS at six weeks and three months $(p<0.05)$ and VAS at three months and six months $(p<0.05)$. At six months, the mean CMS was $83.86 \pm 8.98$ which is better than Kulkarni AU, et al ${ }^{2}$ where mean of CMS at six months was 75.7. We also observed statistically highly significant difference in CMS at three months and six months $(p<0.05)$ with significant improvement in CMS score.

There was statistically significant difference between Neer fracture classification and fracture union time where Neer type II and III fractures united early than Neer type IV $(p<0.05)$ but there was statistically non significance between Neer fracture classification and patient satisfaction at 3 months $(p>0.05)$ and 6 months $(p>0.05)$.

\section{CONCLUSION}

Displaced proximal humerus fracture when treated surgically with JESS has good functional and radiological outcome. It is a light weight implant and easy to apply. Moreover, it is effective in early reduction of pain, prevents stiffness by virtue of its early ROM and ensures early fracture union with minimal manageable minor complications.

There were certain limitations to our study

Small sample size

\section{Single centered study}

The duration of follow-up was only six months, so the long-term outcome could not be evaluated

- The comparison for the union time was different for different studies because of the lack of definitive criteria by which union time of all of the studies could be properly compared

- No blinding techniques were used

\section{CONFLICT OF INTEREST}

None

\section{REFRENCES}

1. Lind T, Krøner K, Jensen J. The epidemiology of fractures of the proximal humerus. Archives of orthopaedic and trauma surgery. 1989;108(5):285-7.

2. Kulkarni AU, Kulkarni UM. Proximal Humerus Fractures Managed With Joshi External Stabilizing System. Techniques in Shoulder \& Elbow Surgery. 2020;21(1):30-2.

3. Palvanen M, Kannus P, Niemi S, Parkkari J. Update in the epidemiology of proximal humeral fractures. Clinical Orthopaedics and Related Research (1976-2007). 2006;442:87-92.

4. Jaura G, Sikdar J, Singh S. Long term results of PHILOS plating and percutaneous $\mathrm{K}$-wire fixation in proximal humerus fractures in the elderly. Malaysian Orthopaedic Journal. 2014;8(1):4.

5. Ghosh S, Ghosh D, Datta S, Chaudhuri A, Roy DS, Chowdhury A. External fixation by Joshi's external stabilizing system in cases of proximal humerus fractures in elderly subjects. Journal of the Scientific Society. 2013;40(2):99.

6. Gupta AK, Harris JD, Erickson BJ, Abrams GD, Bruce B, McCormick F, et al. Surgical management of complex proximal humerus fractures - a systematic review of 92 studies including 4500 patients. Journal of Orthopaedic Trauma. 2015;29(1):549.

7. Arshad N, Bashir J, Bashir S. Short term functional outcome of jess (Joshi's external stabilisation system) in proximal humours fractures in adults: A prospective study. International Journal of Orthopaedics. 2020;6(4):765-70.

8. Magovern B, Ramsey ML. Percutaneous fixation of proximal humerus fractures. Orthopedic Clinics of North America. 2008;39(4):405-16.

9. Standring S. Gray's anatomy E-Book: the anatomical basis of clinical practice: Elsevier Health Sciences; 2020.

10. Kilcoyne R, Shuman WP, Matsen 3rd F, Morris M, Rockwood CA. The Neer classification of displaced proximal humeral fractures: spectrum of findings on plain radiographs and CT scans. American Journal of Roentgenology. 1990;154(5):102933. 
11. Crichton N. Visual analogue scale (VAS). J Clin Nurs. 2001;10(5):706-6.

12. Azhagan S. A prospective study on functional and radiological outcome of proximal humeral fractures treated with locking compression plates. International Journal of Orthopaedics. 2017;3(3):472-6.

13. Constant C, Murley A. A clinical method of functional assessment of the shoulder. Clinical Orthopaedics and Related Research. 1987(214):160-4.

14. Herscovici Jr D, Saunders DT, Johnson MP, Sanders R, DiPasquale T. Percutaneous fixation of proximal humeral fractures. Clinical Orthopaedics and Related Research. 2000;375:97-104.

15. Joshi AK, Giroti C, Gotecha D, Ahmad F, Singh S. Treatment options for proximal humerus fractures: A prospective study. International Journal of Orthopaedics. 2019;5(2):123-7.

16. Vicenti G, Antonella A, Filipponi M, Conserva V, Solarino G, Carrozzo M, et al. A comparative retrospective study of locking plate fixation versus a dedicated external fixator of 3-and 4-part proximal humerus fractures: Results after 5 years. Injury. 2019;50:S80-S8

17. Kocialkowski A, Wallace WA. Closed percutaneous K-wire stabilization for displaced fractures of the surgical neck of the humerus. Injury. 1990;21(4):209-12. 